\title{
Agreement between continuous and intermittent pulmonary artery thermodilution for cardiac output measurement in perioperative and intensive care medicine: a systematic review and meta-analysis
}

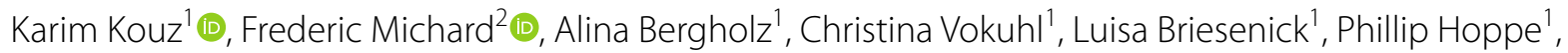
Moritz Flick', Gerhard Schön ${ }^{3}$ (D) and Bernd Saugel ${ }^{1,4^{*}}$ (D)

\begin{abstract}
Background: Pulmonary artery thermodilution is the clinical reference method for cardiac output monitoring. Because both continuous and intermittent pulmonary artery thermodilution are used in clinical practice it is important to know whether cardiac output measurements by the two methods are clinically interchangeable.

Methods: We performed a systematic review and meta-analysis of clinical studies comparing cardiac output measurements assessed using continuous and intermittent pulmonary artery thermodilution in adult surgical and critically ill patients. 54 studies with 1522 patients were included in the analysis.
\end{abstract}

Results: The heterogeneity across the studies was high. The overall random effects model-derived pooled estimate of the mean of the differences was 0.08 (95\%-confidence interval 0.01 to 0.16$) \mathrm{L} / \mathrm{min}$ with pooled $95 \%$-limits of agreement of -1.68 to $1.85 \mathrm{~L} / \mathrm{min}$ and a pooled percentage error of 29.7 (95\%-confidence interval 20.5 to 38.9$) \%$.

Conclusion: The heterogeneity across clinical studies comparing continuous and intermittent pulmonary artery thermodilution in adult surgical and critically ill patients is high. The overall trueness/accuracy of continuous pulmonary artery thermodilution in comparison with intermittent pulmonary artery thermodilution is good (indicated by a pooled mean of the differences $<0.1 \mathrm{~L} / \mathrm{min}$ ). Pooled $95 \%$-limits of agreement of -1.68 to $1.85 \mathrm{~L} / \mathrm{min}$ and a pooled percentage error of $29.7 \%$ suggest that continuous pulmonary artery thermodilution barely passes interchangeability criteria with intermittent pulmonary artery thermodilution.

PROSPERO registration number CRD42020159730.

Keywords: Cardiac index, Cardiovascular dynamics, Hemodynamic monitoring, Indicator dilution method, Pulmonary artery catheterization, Right heart catheterization, Swan-Ganz catheter

\footnotetext{
*Correspondence: bernd.saugel@gmx.de

${ }^{1}$ Department of Anesthesiology, Center of Anesthesiology and Intensive

Care Medicine, University Medical Center Hamburg-Eppendorf, Martinistrasse 52, 20246 Hamburg, Germany

Full list of author information is available at the end of the article
}

\section{Background}

Cardiac output $(\mathrm{CO})$ monitoring is a mainstay of hemodynamic management in high-risk patients having major surgery and in critically ill patients with circulatory shock $[1,2]$. Numerous technologies are available to measure or estimate $\mathrm{CO}[3-6]$. Thermodilution methods allow permits use, sharing, adaptation, distribution and reproduction in any medium or format, as long as you give appropriate credit to the original author(s) and the source, provide a link to the Creative Commons licence, and indicate if changes were made. The images or other third party material in this article are included in the article's Creative Commons licence, unless indicated otherwise in a credit line to the material. If material is not included in the article's Creative Commons licence and your intended use is not permitted by statutory regulation or exceeds the permitted use, you will need to obtain permission directly from the copyright holder. To view a copy of this licence, visit http://creativecommons.org/licenses/by/4.0/. The Creative Commons Public Domain Dedication waiver (http://creativeco mmons.org/publicdomain/zero/1.0/) applies to the data made available in this article, unless otherwise stated in a credit line to the data. 
$\mathrm{CO}$ calculation based on the Stewart-Hamilton principle; after injection of a known amount of indicator the change in indicator concentration downstream in the circulation is related to blood flow [7-9].

Pulmonary artery thermodilution remains the clinical reference method for $\mathrm{CO}$ monitoring [10]. For intermittent pulmonary artery thermodilution a fluid bolus with known volume and temperature is manually injected into the right atrium through the proximal port of a pulmonary artery catheter (PAC) and subsequent temperature changes over time are detected by an integrated thermistor more distal in the pulmonary artery [8]. To minimize measurement error and account for cyclic changes in $\mathrm{CO}$ throughout the respiratory cycle, $\mathrm{CO}$ is calculated based on several consecutive thermodilution $\mathrm{CO}$ measurements [8].

In contrast to intermittent pulmonary artery thermodilution, continuous pulmonary artery thermodilution enables $\mathrm{CO}$ to be measured automatically (i.e., without the need for manual indicator injection) [11]. PACs for continuous pulmonary artery thermodilution are equipped with a thermal filament heating up the blood in the right ventricle in a random binary sequence [11]. Changes in blood temperature are detected downstream by an integrated thermistor near the tip of the PAC. Based on the detected blood temperature changes, $\mathrm{CO}$ is continuously calculated using a stochastic system identification principle and an averaged $\mathrm{CO}$ value is provided by the monitor [11].

Because both continuous and intermittent pulmonary artery thermodilution are used in clinical practice it is important to know whether $\mathrm{CO}$ measurements by the two methods are clinically interchangeable. We, therefore, performed a systematic review and meta-analysis of clinical studies comparing $\mathrm{CO}$ measurements assessed using continuous and intermittent pulmonary artery thermodilution.

\section{Methods}

\section{Study design and registration}

In accordance with the Preferred Reporting Items for Systematic Reviews and Meta-Analyses (PRISMA) statement [12] we performed a systematic review and meta-analysis of clinical studies comparing continuous pulmonary artery thermodilution-derived $\mathrm{CO}$ measurements $\left(\mathrm{CO}_{\text {cont; }}\right.$, test method) with intermittent pulmonary artery thermodilution-derived $\mathrm{CO}$ measurements $\left(\mathrm{CO}_{\text {int }}\right.$; reference method) in adult patients having surgery or critically ill patients treated in the intensive care unit. This systematic review and meta-analysis was registered in the International Prospective Register of Systematic Reviews (PROSPERO; registration number CRD42020159730).

\section{Eligibility criteria}

For this systematic review and meta-analysis, we considered studies published in English between January 1st, 1975 and December 31st, 2019 comparing $\mathrm{CO}_{\text {cont }}$ and $\mathrm{CO}_{\text {int }}$ in adult (age $\geq 18$ years) surgical or critically ill patients that report extractable or calculable mean of the differences between $\mathrm{CO}_{\text {cont }}$ and $\mathrm{CO}_{\text {int }}$ with corresponding standard deviation (SD) and/or 95\%-limits of agreement (95\% LOA). We did not consider correspondences or case reports.

\section{Information sources and search strategy}

The electronic databases PubMed, Web of Science, and the Cochrane Library were systematically searched using a priori defined search strategies. As an example, the full electronic search strategy for PubMed is provided in Additional file 1. Further, the reference lists of the identified studies and the reference lists of previous reviews were searched to find additional eligible studies that had not been identified during the initial systematic database search.

\section{Study selection}

Titles and abstracts of all identified studies were screened by three investigators (PH, MF, BS). The fulltext of potentially eligible studies was used to assess study eligibility based on the above-mentioned predefined eligibility criteria. Discrepancies were resolved by discussion among the three investigators.

\section{Data collection process and data items}

Four different investigators (KK, AB, CV, LB) independently extracted the data from the included studies and data were checked for consistency. Discrepancies were discussed and resolved based on the original data. We extracted data on the results of comparative statistics, i.e., the mean of the differences between $\mathrm{CO}_{\text {cont }}$ and $\mathrm{CO}_{\text {int }}$ with SD, 95\% LOA, and the percentage error (PE) [13]. We report the mean of the differences between $\mathrm{CO}_{\text {cont }}$ and $\mathrm{CO}_{\text {int }}$ as $\mathrm{CO}_{\text {cont }}-\mathrm{CO}_{\text {int }}$. We re-calculated the mean of the differences for studies reporting the mean of the differences as $\mathrm{CO}_{\text {int }}-\mathrm{CO}_{\text {cont }}$ accordingly. If not provided in the studies, the SD of the mean of the differences was re-calculated as (upper 95\% LOA mean of the differences)/1.96. For studies not providing the PE but reporting mean $\mathrm{CO}_{\text {cont }}$ and mean $\mathrm{CO}_{\text {int }}$, the PE was calculated as (1.96 - SD of the mean of the differences $) /\left(\right.$ mean of $\mathrm{CO}_{\text {cont }}$ and $\left.\mathrm{CO}_{\text {int }}\right)$.

In addition to the results of comparative statistics, we extracted data regarding the study setting (operating room or intensive care unit), the patient population, the number of patients, the total number of measurement pairs, and the year of publication. 


\section{Risk of bias in individual studies}

Based on the Quality Assessment of Diagnostic Accuracy Studies guidelines (QUADAS-2) [14] we used an adapted questionnaire (Additional file 2) to assess study quality by objectively performing judgments on bias and applicability of the included studies [14-16]. Risk of bias classification is based on different signaling questions of different domains that were marked with "yes", "no" or "unclear" which finally results in classifying these domains as "low", "high" or "unclear" risk of bias. Concerns about applicability of the included studies were rated as "low", "high" or "unclear". An independent quality assessment of each included study was performed by three investigators (KK, $A B, L B)$ and discrepancies were resolved by discussion among the three investigators.

\section{Principle summary measures}

The mean of the differences between $\mathrm{CO}_{\text {cont }}$ and $\mathrm{CO}_{\text {int }}$ of the individual studies is the principal summary measure of the current meta-analysis. We used a random effects model for means as outcomes with restricted maximum likelihood as the estimator to summarize the mean of the differences, the SD of the mean of the differences, and the sample size. This random effects model derives a pooled estimate of the mean of the differences that represents the trueness/accuracy of $\mathrm{CO}_{\text {cont }}$ compared to $\mathrm{CO}_{\text {int }}$.

For each study, we calculated the 95\%-confidence interval $(95 \% \mathrm{CI})$ for the reported/calculated mean of the differences between $\mathrm{CO}_{\text {cont }}$ and $\mathrm{CO}_{\text {int }}$ as $1.96 \cdot$ standard error of the mean ( $\mathrm{SD} / \sqrt{ }$ sample size) to account for study sample size. We summarized these $95 \%$ CIs with the random effects model and report the resulting overall random effects model-derived pooled estimate of the $95 \%$ CI.

Further, we report overall random effects modelderived pooled estimates of 95\% LOA.

We summarized the PE using a random effects model for proportions with DerSimonian-Laird as the estimator [17] and report the overall random effects model-derived pooled estimate of the PE with $95 \%$ CI. We defined clinical interchangeability between $\mathrm{CO}_{\text {cont }}$ and $\mathrm{CO}_{\text {int }}$ based on the established 30\% PE threshold [13]. Heterogeneity and inconsistency were assessed by means of Cochran's $\mathrm{Q}$ and $\mathrm{I}^{2}$.

\section{Synthesis of results}

The database includes all relevant data to perform the meta-analysis. To obtain overall random effects modelderived pooled estimates, a random effects model was computed for each outcome. We reported Cochran's $\mathrm{Q}$ as a measure of heterogeneity and $\mathrm{I}^{2}$ as a measure of consistency.

\section{Risk of publication bias across studies}

We calculated funnel plots with corresponding Eggers regression tests for asymmetry to address the potential problem of selective reporting [18].

\section{Subgroup analyses, additional analyses}

We performed subgroup analyses considering the factors "setting" (operating room and intensive care unit) and "patient population" (liver transplantation and cardiac surgery).

Additionally, we investigated the relation between the mean of the differences between $\mathrm{CO}_{\text {cont }}$ and $\mathrm{CO}_{\text {int }}$ from individual studies and a) the reported mean $\mathrm{CO}_{\text {int }}$ and $\mathrm{b}$ ) the year of publication.

\section{Statistical software}

We used the software $\mathrm{R}$ version 4.0.2 ( $\mathrm{R}$ Foundation for Statistical Computing. Vienna, Austria) with the R-package metafor version 2.4-0 for statistical analyses [19].

\section{Results \\ Study selection}

After removal of duplicates, we identified 426 different records based on the initial electronic database search (Fig. 1). We excluded 362 records after title and abstract screening. Full-text screening of the remaining 64 articles identified 54 studies fulfilling our predefined inclusion criteria [20-73]. Six studies were divided into two studies each for the following reasons: measurements before and after caval clamping/graft perfusion during liver transplantation [26], measurements reported separately for infusion rates $>1000 \mathrm{~mL} / \mathrm{h}$ and $\leq 1000 \mathrm{~mL} / \mathrm{h}$ [41], measurements with different PAC devices [60,72], measurements reported separately for patients with an ejection fraction higher or lower than 45\% [65], and measurements reported separately for patients with a $\mathrm{CO}$ higher or lower than $8 \mathrm{~L} / \mathrm{min}$ [36]. One study was divided into four studies because different software versions and different fluid bolus temperatures were used [67].

\section{Study characteristics}

We included a total number of 1,522 individual patients in the final analysis with a median of 21 patients included per study (minimum: 7 patients, maximum: 84 patients). All studies reported the number of measurement pairs except for one study. The total number of reported measurement pairs was 17,920 with a median of 168 (interquartile range 108 and 238) measurement pairs per study. In 51 of the 54 studies, the mean of the differences was reported; for the remaining three studies the mean of the differences was calculated. In 24 of the 54 studies, 95\% LOA were reported; for 30 studies 


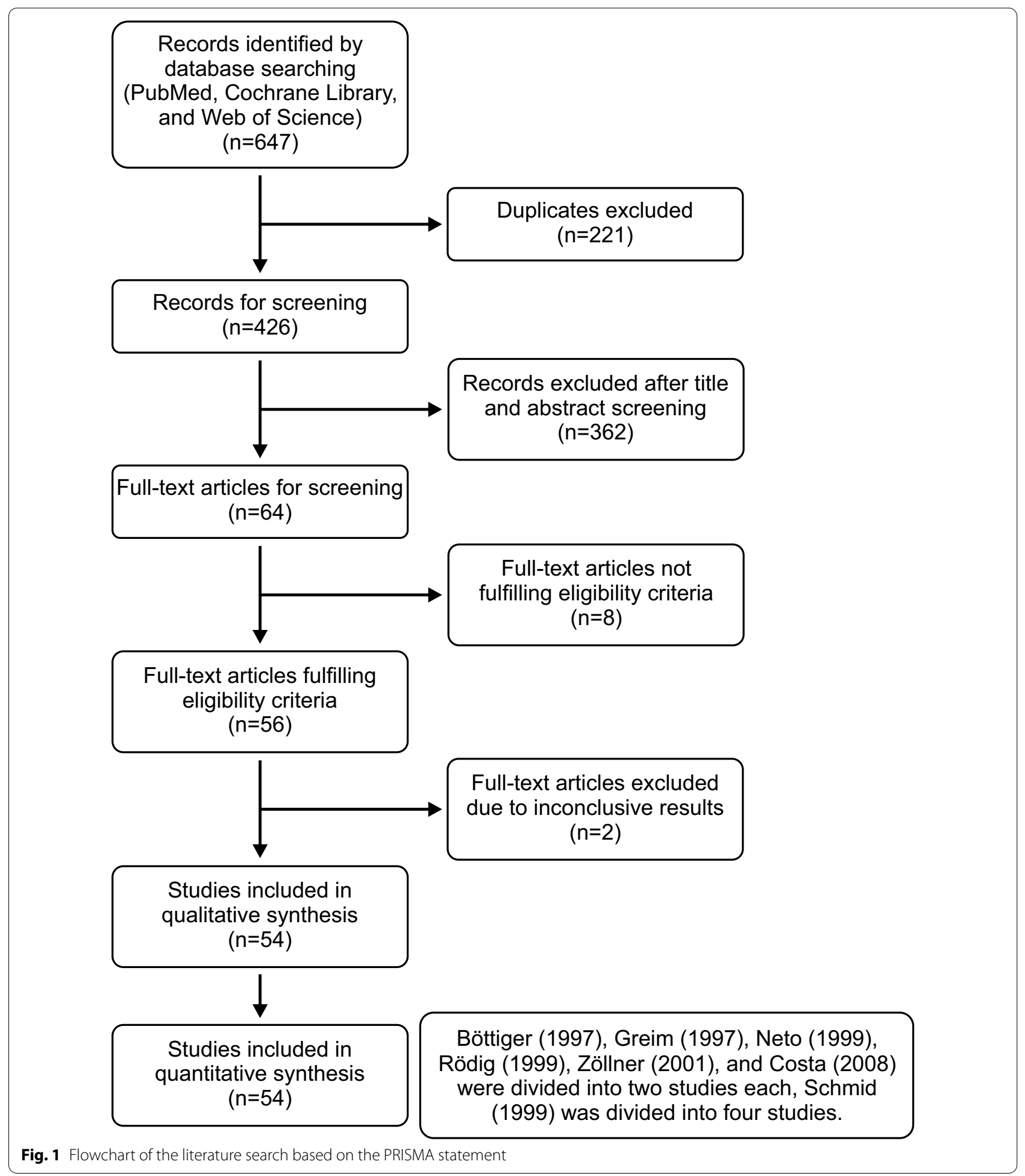

95\% LOA were calculated. In 11 of the 54 studies, the PE was reported; for 16 studies the PE was calculated. In 23 of the 54 studies, the mean values of $\mathrm{CO}_{\text {cont }}$ and
$\mathrm{CO}_{\text {int }}$ were reported or calculated. A summary of the included studies and $\mathrm{CO}$ measurement data is provided in Additional file 3. 


\section{Risk of bias in individual studies}

The adapted QUADAS-2 questionnaire was used to assess the risk of bias in the included studies (Additional file 4). In 19 studies, the risk of bias was identified to be "unclear" or "high" at least for one domain, in six studies, the risk of bias was identified to be "high" at least for one domain.

\section{Overall meta-analysis}

Individual means of the differences between $\mathrm{CO}_{\text {cont }}$ and $\mathrm{CO}_{\text {int }}$ with SD and 95\% LOA for each study are shown in Additional file 3. The overall random effects modelderived pooled estimate of the mean of the differences between $\mathrm{CO}_{\text {cont }}$ and $\mathrm{CO}_{\text {int }}$ was 0.08 (95\% CI 0.01 to 0.16 ) $\mathrm{L} / \mathrm{min}$ with pooled $95 \% \mathrm{LOA}$ of -1.68 to $1.85 \mathrm{~L} / \mathrm{min}$ (heterogeneity: $\left.\mathrm{Q}=200.1(P<0.001), \mathrm{I}^{2}=75 \%\right)$ (Fig. 2 ).

The overall random effects model-derived pooled estimate of the PE was $29.7 \%$ with $95 \%$ CI of 20.5 to $38.9 \%$ (heterogeneity: $\left.\mathrm{Q}=281.3(P<0.001), \mathrm{I}^{2}=90 \%\right)$ (Fig. 3). The PE was $\leq 30 \%$ in 19 out of 27 studies (70\%).

\section{Risk of publication bias across studies}

Funnel plots indicating the risk of publication bias across studies including Eggers regression tests are shown in Additional file 5 for $\mathrm{CO}(P=0.843)$, and Additional file 6 for PE $(P=0.474)$.

\section{Subgroup analyses, additional analyses}

We performed subgroup analyses considering the factors "setting" (operating room and intensive care unit), "patient population" (liver transplantation and cardiac surgery), and "availability of the PE" (studies where the $\mathrm{PE}$ was reported or calculable and studies where the PE was not reported or calculable).

For patients studied in the operating room $[20,22,26$, $34,37,38,41,44,48,49,52,62,64,69]$, the overall random effects model-derived estimate of the mean of the differences was 0.14 (95\% CI 0.00 to 0.28$) \mathrm{L} / \mathrm{min}$ with pooled $95 \% \mathrm{LOA}$ of -2.03 to $2.44 \mathrm{~L} / \mathrm{min}$ (Additional file 7). For patients studied in the intensive care unit [21, $23,24,27-29,31-33,35,36,39,40,42,45,46,51,53-60$, 66-68, 70-73], the overall random effects model-derived estimate of the mean of the differences was 0.07 (95\% CI -0.04 to 0.17$) \mathrm{L} / \mathrm{min}$ with pooled $95 \% \mathrm{LOA}$ of -1.66 to $1.76 \mathrm{~L} / \mathrm{min}$ (Additional file 8 ).

For patients having liver transplantation [20, 22, 26, $35,36,38,41]$, the overall random effects model-derived estimate of the mean of the differences was 0.07 (95\% CI -0.26 to 0.40$) \mathrm{L} / \mathrm{min}$ with pooled $95 \% \mathrm{LOA}$ of -2.89 to $3.01 \mathrm{~L} / \mathrm{min}$ (Additional file 9). For patients having cardiac surgery $[23,25,27,30-32,34,39,43-45,47-49,52$, $54,56,60,61,63-65,67,69,70,72,73]$, the overall random effects model-derived estimate of the mean of the differences was 0.09 (95\% CI -0.01 to 0.18$) \mathrm{L} / \mathrm{min}$ with pooled $95 \% \mathrm{LOA}$ of -1.38 to $1.54 \mathrm{~L} / \mathrm{min}$ (Additional file 10).

There were no clinically meaningful differences in the mean of the differences and the 95\% LOA between studies with reported/calculable $\mathrm{PE}$ and studies without reported/calculable PE (Additional files 11 and 12).

The mean of the differences between $\mathrm{CO}_{\text {cont }}$ and $\mathrm{CO}_{\text {int }}$ from individual studies was not influenced by the reported mean $\mathrm{CO}_{\text {int }}$ (Additional file 13) or the year of publication (Additional file 14).

\section{Discussion}

In this meta-analysis of clinical studies comparing $\mathrm{CO}_{\text {cont }}$ and $\mathrm{CO}_{\text {int }}$ in adult surgical and critically ill patients, the heterogeneity across studies was high. The overall random effects model-derived pooled estimate of the mean of the differences between $\mathrm{CO}_{\text {cont }}$ and $\mathrm{CO}_{\text {int }}$ was $0.08 \mathrm{~L} /$ min with pooled $95 \% \mathrm{LOA}$ of -1.68 to $1.85 \mathrm{~L} / \mathrm{min}$ and a pooled PE of 29.7 (95\% CI 20.5 to 38.9 )\%.

In $\mathrm{CO}$ method comparison studies, the agreement between a test and a reference method is described by the trueness (often called "accuracy") and precision of agreement [74-76] based on Bland-Altman analysis [77-79]. In Bland-Altman plots, the difference between measurements with a test and a reference method is plotted against the mean of the two measurements [77-79]. The mean of the differences (often called "bias") reflects the trueness of test method measurements, the SD and 95\% LOA of the mean of the differences reflect the precision of agreement [74-76]. The PE is used frequently in $\mathrm{CO}$ method comparison studies to characterize the precision of agreement; the PE is $1.96 \mathrm{SD}$ of the mean of the differences between measurements divided by the mean value of all measurements [13]. In their landmark study, Critchley et al. proposed $28.3 \%$, rounded up to $30 \%$, as the PE threshold defining interchangeability [13]. Nevertheless, one should keep in mind that the PE threshold of $28.3 \%$ is based on the assumption that the precision of method of both the test method and the reference method are $20 \%$. Because the precision of method is not exactly known, using a 30\% PE threshold may lead to misinterpretations concerning the clinical interchangeability of $\mathrm{CO}_{\text {cont }}$ and $\mathrm{CO}_{\text {int }}$.

In this meta-analysis, the overall random effects modelderived pooled estimate of the mean of the differences between $\mathrm{CO}_{\text {cont }}$ and $\mathrm{CO}_{\text {int }}$ was $<0.1 \mathrm{~L} / \mathrm{min}$-which is less than a $2 \%$ difference for an average adult $\mathrm{CO}$ of 5 to $6 \mathrm{~L} /$ min. This meta-analysis thus suggests a good trueness/ accuracy of $\mathrm{CO}_{\text {cont }}$ compared with $\mathrm{CO}_{\text {int }}$ when looking at the overall pooled mean of the differences. However, a low pooled mean of the differences in meta-analyses can be misleading because averaging study results with 


Study

Böttiger (1997) B
Albert (1999)
Costa (2014)
Ishihara (2004)
Zöllner (1999)
Costa (2008) A
Burchell (1997)
Rauch (2002)
Cho (2016)
Bao (2008)
Mihm (1998)
Monchi (1998)
Nelson (2001)
Singh (2002)
Zöllner (2001) A
Neto (1999) A
Lazor (1997)
Zöllner (2001) B
Boldt (1994)
Böttiger (1995)
Padua (2003)
Yelderman (1992)
Neto (1999) B
Jacquet (1996)
Seguin (1998)
Schmid (1999) A
Della Rocca (2002)
Hamm (2010)
Böttiger (1996)
Rödig (1999) B
Thierry (2003)
Schmid (1999) D
Boyle (1997)
Ditmyer (1995)
Peyton (2014)
Rödig (1999) A
Rödig (1998)
Della Rocca (2003)
Kotake (2009)
Schmid (1999) B
Greim (1997) A
Ganter (2016)
Böttiger (1997) A
Cecchini (2012)
Mielck (2003)
Cecconi (2010)
Jakobsen (1995)
Bendjelid (2006)
Button (2007)
Haller (1995)
Schmid (1999) C
Kotake (2003)
Cathelyn (1999)
Le Tulzo (1996)
Leather (2004)
Hogue (1994)
Sakka (2000)
Costa (2008) B
Manecke (2007)
Akiyoshi (2011)
Lefrant (1995)
Greim (1997) B

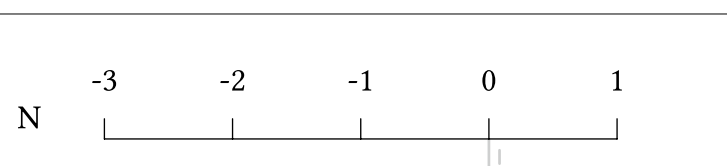

Mean
of the
differences

(95\%differences confidence interval)

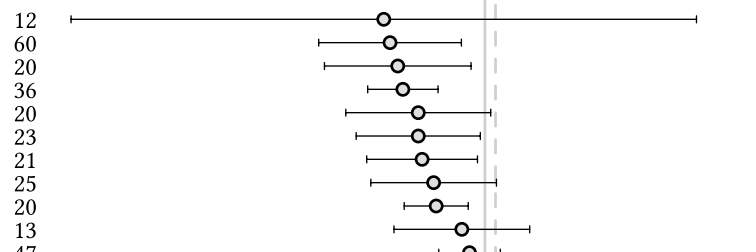

-0.79
-0.74
-0.68
-0.64
-0.52

$(-3.23,1.65)$

$(-1.30,-0.18$

$(-1.25,-0.11)$

$(-1.09,0.05)$

$(-1.00,-0.04$

$(-0.92,-0.06)$

$(-0.89,0.09)$

$-0.49$

$-0.40$

$-0.38$

$-0.18$

$-0.12$

$-0.12$

$-0.11$

-0.10
-0.09

-0.09
-0.07

-0.07
-0.06

$-0.06$

$-0.03$

$-0.02$

$-0.02$

$-0.02$

$-0.01$

$-0.01$

-0.00
0.00

0.00
0.02

0.02
0.03

0.03
0.05

0.06
0.07

0.07

0.07

0.07

0.10

0.10

0.12
0.13

0.13
0.15

0.15

0.20

0.20
0.23

0.23

0.24
0.27

0.28

0.28
0.30

0.31

0.31
0.33

Random effects model for all

Heterogeneity: $Q=200.1(P<0.001)$

$$
\mathrm{I}^{2}=75 \%
$$

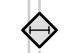

0.08

$(0.01,0.16)$

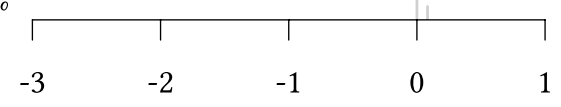

\section{Mean of the differences $\mathrm{CO}[\mathrm{L} / \mathrm{min}]$}

Fig. 2 Forest plot for cardiac output. Forest plot showing the results of the meta-analysis for cardiac output (CO) with mean of the differences (dots) calculated as the mean of continuous pulmonary artery thermodilution-derived CO measurements minus intermittent pulmonary artery thermodilution-derived CO measurements and corresponding 95\%-confidence interval (bars) per individual study in relation to the overall random effects model-derived pooled estimate (vertical dashed line). Heterogeneity is presented with Cochran's $Q$ and I $^{2}$. N, number of patients per study. Böttiger and colleagues [26], Costa and colleagues [36], Greim and colleagues [41], Neto and colleagues [60], Rödig and colleagues [65], and Zöllner and colleagues [72] are treated as two studies in the analysis (A and B). Schmid and colleagues [67] is treated as four studies in the analysis (A, B, C, and D) 


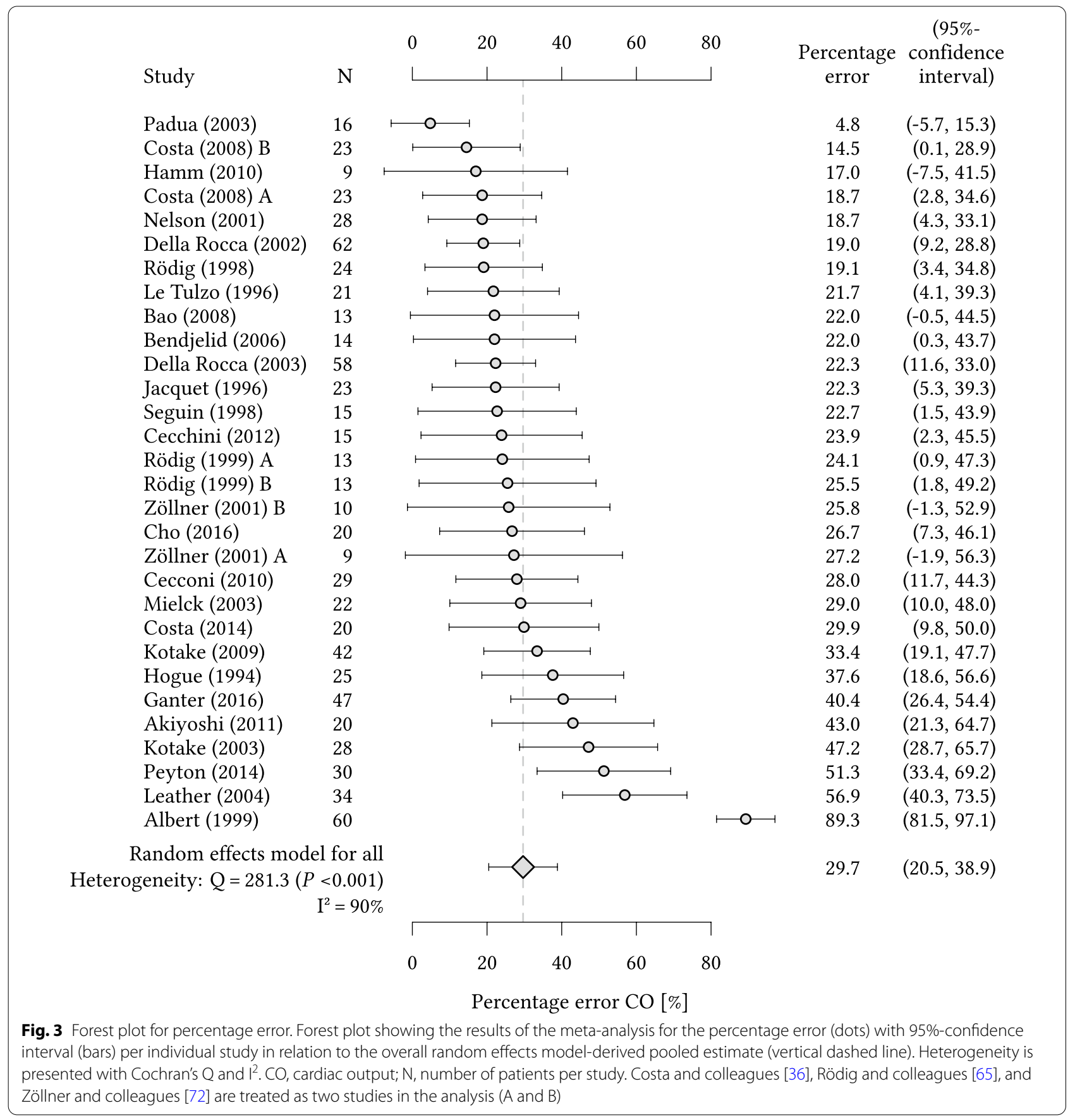

negative and positive means of the differences of similar absolute amount can result in a very low pooled mean of the differences despite marked measurement differences in single studies. In this meta-analysis, studies reporting an overestimation and those reporting an underestimation of $\mathrm{CO}_{\text {cont }}$ compared to $\mathrm{CO}_{\text {int }}$ neutralized each other, as illustrated in Fig. 2.
Regarding the precision of agreement between $\mathrm{CO}_{\text {cont }}$ and $\mathrm{CO}_{\text {int }}$ this meta-analysis revealed that the pooled 95\% LOA of the mean of the differences between $\mathrm{CO}_{\text {cont }}$ and $\mathrm{CO}_{\text {int }}$ were -1.68 to $1.85 \mathrm{~L} / \mathrm{min}$. The overall random effects model-derived pooled estimate of the PE was 29.7 (95\% CI 20.5 to 38.9 )\%-thus suggesting that $\mathrm{CO}_{\text {cont }}$ barely passes interchangeability criteria with $\mathrm{CO}_{\text {int }}[13]$. However, the PE was only available for half of all studies 
because the PE per se or mean $\mathrm{CO}$ values necessary for post-hoc PE calculation were not always reported. Nevertheless, 95\% CIs were similar in studies with reported or calculable PE and studies where the PE was not reported or calculable suggesting that the PE for all studies would probably also be close to $30 \%$.

This meta-analysis showed a large variability in results between studies, with means of the differences reported in single studies ranging from -0.79 to $1.00 \mathrm{~L} / \mathrm{min}$ and PEs ranging from 4.8 to $89.3 \%$. This variability strongly suggests that the measurement performance of $\mathrm{CO}_{\text {cont }}$ is influenced by various factors, that may include patient characteristics, the clinical setting, and cardiovascular dynamics. Even subgroups of studies were heterogeneous. For example, the "operating room" subgroup included patients having different types of surgery, the "intensive care unit" subgroup included patients with and without circulatory shock requiring different vasopressor and inotropic support, and the "cardiac surgery" subgroup included patients studied either during or after surgery. It is important to bear in mind that the measurement performance is context-sensitive when interpreting validation studies of any CO monitoring system [80].

Intermittent pulmonary artery thermodilution remains the clinical reference method for $\mathrm{CO}$ monitoring and therefore is frequently used as the "gold standard" in method comparison studies [10]. Continuous pulmonary artery thermodilution offers the opportunity to measure $\mathrm{CO}$ automatically without the need for manual indicator injection, thus reducing contamination risk and saving time [81]. Although "continuous" suggests that this PAC technology provides real-time $\mathrm{CO}$ measurements, it actually provides "semi-continuous", averaged $\mathrm{CO}$ values $[11,81]$. The averaging procedure improves the signalto-noise ratio but may cause a time delay of up to several minutes. This time delay may become relevant when hemodynamics change rapidly, e.g., during dynamic tests such as passive leg raising and during therapeutic interventions such as fluid or vasopressor administration $[8$, 82, 83].

In today's clinical practice, PACs are mainly used in patients having cardiac surgery, liver transplantation, and in critically ill patients with circulatory shock, especially with right ventricular dysfunction [10, 84]. Using a PAC allows monitoring of $\mathrm{CO}$, mixed venous oxygen saturation, and intravascular pressure and thus provides important information on cardiovascular dynamics [85]. There is nonetheless an ongoing debate on whether or not PACs still have a place in daily clinical practice [86-88]. Some trials showed no clinical benefit of using the PAC without treatment protocols in critically ill patients $[89,90]$ or cardiac surgery patients [91]. Additionally, there are now various methods to measure or estimate $\mathrm{CO}$ less invasively or even non-invasively $[3,6]$. The clinical use of the PAC thus decreased over the last years in critically ill patients and in surgical patients [92, 93].

Although intermittent and continuous pulmonary thermodilution methods are widely used, we are not aware of any meta-analysis investigating the overall agreement between the two methods. In contrast, several meta-analyses have already been published for Doppler [94, 95], bioimpedance [15, 94], as well as invasive and non-invasive pulse contour methods $[15,16,94]$. They all reported pooled $\mathrm{PE}$ values ranging between 40 and $50 \%$.

We only investigated the absolute agreement between $\mathrm{CO}_{\text {cont }}$ and $\mathrm{CO}_{\text {int }}$ and did not analyze the trending ability of $\mathrm{CO}_{\text {cont }}$. The ability to track changes in $\mathrm{CO}$ is actually the main expectation clinicians may have from a continuous monitoring system over an intermittent technique. Unfortunately, most studies of this meta-analysis did not report concordance rates or polar plots, so that we were unable to assess the ability of continuous pulmonary thermodilution to track changes in CO. Furthermore, several studies [19 of 54 (35\%)] had a risk of bias classification of "unclear" or "high" that may further influence the final results of this meta-analysis. About half of the included studies [26 of 54 (48\%)] were performed before the year 2000, and only 6 (11\%) studies after 2010.

\section{Conclusion}

The heterogeneity across clinical studies comparing $\mathrm{CO}_{\text {cont }}$ and $\mathrm{CO}_{\text {int }}$ in adult surgical and critically ill patients is high. The overall trueness/accuracy of $\mathrm{CO}_{\text {cont }}$ in comparison with $\mathrm{CO}_{\text {int }}$ is good (indicated by a pooled mean of the differences $<0.1 \mathrm{~L} / \mathrm{min}$ ). Pooled $95 \% \mathrm{LOA}$ of -1.68 to $1.85 \mathrm{~L} / \mathrm{min}$ and a pooled PE of 29.7 (95\% CI 20.5 to 38.9$) \%$ suggest that $\mathrm{CO}_{\text {cont }}$ barely passes interchangeability criteria with $\mathrm{CO}_{\text {int. }}$. The PE was $\leq 30 \%$ in two-thirds of studies with available PE.

\footnotetext{
Abbreviations

95\% Cl: 95\%-confidence interval; 95\% LOA: 95\%-limits of agreement; CO: Cardiac output; $\mathrm{CO}_{\text {cont: }}$ Continuous pulmonary artery thermodilution-derived $\mathrm{CO}$ measurements; $\mathrm{CO}_{\text {int }}$ Intermittent pulmonary artery thermodilution-derived CO measurements; PAC: Pulmonary artery catheter; PE: Percentage error; PRISMA: Preferred Reporting Items for Systematic Reviews and Meta-Analyses; PROSPERO: International Prospective Register of Systematic Reviews; QUADAS: Quality Assessment of Diagnostic Accuracy Studies guidelines; SD: Standard deviation.
} 


\section{Supplementary Information}

The online version contains supplementary material available at https://doi. org/10.1186/s13054-021-03523-7.

Additional file 1. Electronic search strategy for PubMed. This file contains the full electronic search strategy for PubMed.

Additional file 2. Adapted QUADAS-2 questionnaire. This file contains the adapted QUADAS-2 questionnaire that was used to assess study quality by objectively performing judgments on bias and applicability of the included studies.

Additional file 3. Summary of the included studies and cardiac output measurement data. This file contains a table summarizing the included studies and extracted cardiac output measurement data.

Additional file 4. Risk of bias assessment. This file contains the results of the risk of bias assessment of all included studies.

Additional file 5. Funnel plot for cardiac output with Eggers regression test. Funnel plot indicating the risk of publication bias across studies including Eggers regression for cardiac output (CO).

Additional file 6. Funnel plot for the percentage error with Eggers regression test. Funnel plot indicating the risk of publication bias across studies including Eggers regression for the percentage error. CO, cardiac output.

Additional file 7. Forest plot showing subgroup analysis for the setting "operating room". Forest plot showing the results of the subgroup analysis for the setting "operating room" for cardiac output (CO) with mean of the differences (dots) and corresponding 95\%-confidence interval (bars) per individual study in relation to the overall random effects model-derived pooled estimate (vertical dashed line). Heterogeneity is presented with Cochran's $Q$ and $I^{2}$. N, number of patients per study. Böttiger and colleagues [26], and Greim and colleagues [41] are treated as two studies in the analysis ( $A$ and $B$ ).

Additional file 8. Forest plot showing subgroup analysis for the setting "intensive care unit". Forest plot showing the results of the subgroup analysis for the setting "intensive care unit" for cardiac output (CO) with mean of the differences (dots) and corresponding 95\%-confidence interval (bars) per individual study in relation to the overall random effects model-derived pooled estimate (vertical dashed line). Heterogeneity is presented with Cochran's $Q$ and I'. N, number of patients per study. Costa and colleagues [36], Neto and colleagues [60], and Zöllner and colleagues [72] are treated as two studies in the analysis (A and B). Schmid and colleagues [67] is treated as four studies in the analysis (A, B, C, and D).

Additional file 9. Forest plot showing subgroup analysis for patients having liver transplantation. Forest plot showing the results of the subgroup analysis for patients having liver transplantation for cardiac output (CO) with mean of the differences (dots) and corresponding 95\%-confidence interval (bars) per individual study in relation to the overall random effects model-derived pooled estimate (vertical dashed line). Heterogeneity is presented with Cochran's $Q$ and $I^{2}$. N, number of patients per study. Böttiger and colleagues [26], Costa and colleagues [36], and Greim and colleagues [41] are treated as two studies in the analysis (A and B).

Additional file 10. Forest plot showing subgroup analysis for patients having cardiac surgery. Forest plot showing the results of the subgroup analysis for patients having cardiac surgery for cardiac output (CO) with mean of the differences (dots) and corresponding 95\%-confidence interval (bars) per individual study in relation to the overall random effects model-derived pooled estimate (vertical dashed line). Heterogeneity is presented with Cochran's $Q$ and $I^{2}$. N, number of patients per study. Neto and colleagues [60], Rödig and colleagues [65], and Zöllner and colleagues [72] are treated as two studies in the analysis (A and B). Schmid and colleagues [67] is treated as four studies in the analysis (A, B, C, and D).

Additional file 11. Forest plot showing subgroup analysis for studies with reported or calculable percentage error. Forest plot showing the results of the subgroup analysis for studies with reported or calculable percentage error for cardiac output (CO) with mean of the differences (dots) and corresponding 95\%-confidence interval (bars) per individual study in relation to the overall random effects model-derived pooled estimate (vertical dashed line). Heterogeneity is presented with Cochran's $Q$ and $I^{2}$. N, number of patients per study. Costa and colleagues [36], Rödig and colleagues [65], and Zöllner and colleagues [72] are treated as two studies in the analysis ( $A$ and $B$ ).

Additional file 12. Forest plot showing subgroup analysis for studies without reported or calculable percentage error. Forest plot showing the results of the subgroup analysis for studies without reported or calculable percentage error for cardiac output (CO) with mean of the differences (dots) and corresponding 95\%-confidence interval (bars) per individual study in relation to the overall random effects model-derived pooled estimate (vertical dashed line). Heterogeneity is presented with Cochran's $\mathrm{Q}$ and $\mathrm{I}^{2}$. N, number of patients per study. Böttiger and colleagues [26], Greim and colleagues [41], and Neto and colleagues [60], are treated as two studies in the analysis (A and B). Schmid and colleagues [67] is treated as four studies in the analysis (A, B, C, and D).

Additional file 13. Influence of the level of cardiac output. Plot showing the relation between the mean of the differences (dots) with corresponding 95\%-confidence interval (bars) per individual study and mean intermittent pulmonary artery catheter-derived cardiac output (CO) measurement $\left(\mathrm{CO}_{\text {int }}\right)$.

Additional file 14. Influence of the year of publication. Plot showing the relation between the mean of the differences (dots) with corresponding $95 \%$-confidence interval (bars) per individual study and the year of publication. CO, cardiac output.

\section{Acknowledgements}

None.

\section{Authors' contributions}

KK: conception of the review, literature search, writing of the manuscript. FM: conception of the review, literature search, writing of the manuscript. AB: literature search, data extraction, writing of the manuscript. CV: literature search, data extraction, writing of the manuscript. LB: literature search, data extraction, writing of the manuscript. PH: literature search, data extraction, revision of the manuscript for important intellectual content. MF: literature search, data extraction, revision of the manuscript for important intellectual content. GS: statistical analysis, writing of the manuscript. BS: conception of the review, literature search, writing of the manuscript. All authors read and approved the final manuscript.

\section{Funding}

Open Access funding enabled and organized by Projekt DEAL. Support was provided solely from institutional and departmental sources.

\section{Availability of data and materials}

The datasets used and/or analyzed during the current study are available from the corresponding author on reasonable request.

\section{Declarations}

\section{Ethics approval and consent to participate}

Not applicable.

\section{Consent for publication}

Not applicable.

\section{Competing interests}

$\mathrm{KK}, \mathrm{AB}, \mathrm{CV}, \mathrm{PH}, \mathrm{LB}$ and $\mathrm{GS}$ declare that they have no competing interests. FM is the founder and managing director of MiCo (michardconsulting.com), a Swiss consulting and research firm. MiCo does not sell any medical device and FM does not own shares and does not receive royalties from any medical device company. MF has received honoraria for consulting from CNSystems Medizintechnik GmbH (Graz, Austria). BS has received honoraria for consulting, honoraria for giving lectures, and refunds of travel expenses from Edwards Lifesciences (Irvine, CA, USA). BS has received honoraria for consulting, institutional restricted research grants, honoraria for giving lectures, and refunds 
of travel expenses from Pulsion Medical Systems SE (Feldkirchen, Germany). BS has received institutional restricted research grants, honoraria for giving lectures, and refunds of travel expenses from CNSystems Medizintechnik $\mathrm{GmbH}$ (Graz, Austria). BS has received institutional restricted research grants from Retia Medical LLC (Valhalla, NY, USA). BS has received honoraria for giving lectures from Philips Medizin Systeme Böblingen GmbH (Böblingen, Germany). BS has received honoraria for consulting, institutional restricted research grants, and refunds of travel expenses from Tensys Medical Inc. (San Diego, CA, USA).

\section{Author details}

${ }^{1}$ Department of Anesthesiology, Center of Anesthesiology and Intensive Care Medicine, University Medical Center Hamburg-Eppendorf, Martinistrasse 52, 20246 Hamburg, Germany. ${ }^{2}$ MiCo, Denens, Switzerland. ${ }^{3}$ Institute of Medical Biometry and Epidemiology, University Medical Center Hamburg-Eppendorf, Hamburg, Germany. ${ }^{4}$ Outcomes Research Consortium, Cleveland, OH, USA.

Received: 9 December 2020 Accepted: 1 March 2021

Published online: 29 March 2021

\section{References}

1. Vincent JL, Pelosi P, Pearse R, Payen D, Perel A, Hoeft A, et al. Perioperative cardiovascular monitoring of high-risk patients: a consensus of 12. Crit Care. 2015;19(1):224.

2. Cecconi M, De Backer D, Antonelli M, Beale R, Bakker J, Hofer C, et al. Consensus on circulatory shock and hemodynamic monitoring. Task force of the European Society of Intensive Care Medicine. Intensive Care Med. 2014;40(12):1795-815.

3. Saugel B, Vincent J-L. Cardiac output monitoring: how to choose the optimal method for the individual patient. Curr Opin Crit Care. 2018;24(3):165-72.

4. De Backer D, Bakker J, Cecconi M, Hajjar L, Liu DW, Lobo S, et al. Alternatives to the Swan-Ganz catheter. Intensive Care Med. 2018:44(6):730-41.

5. Teboul JL, Saugel B, Cecconi M, De Backer D, Hofer CK, Monnet X, et al. Less invasive hemodynamic monitoring in critically ill patients. Intensive Care Med. 2016;42(9):1350-9.

6. Kouz K, Scheeren TWL, de Backer D, Saugel B. Pulse wave analysis to estimate cardiac output. Anesthesiology. 2021;134(1):119-26.

7. Stewart GN. Researches on the circulation time and on the Influences which affect it. J Physiol. 1897;22(3):159-83.

8. Reuter DA, Huang C, Edrich T, Shernan SK, Eltzschig HK. Cardiac output monitoring using indicator-dilution techniques: basics, limits, and perspectives. Anesth Analg. 2010;110(3):799-811.

9. Hamilton WF, Moore JW, Kinsman JM, Spurling RG. Simultaneous determination of the pulmonary and systemic circulation times in man and of a figure related to the cardiac output. Am J Physiol. 1928;84(2):338-44.

10. Rajaram SS, Desai NK, Kalra A, Gajera M, Cavanaugh SK, Brampton W, et al. Pulmonary artery catheters for adult patients in intensive care. Cochrane Database Syst Rev. 2013;2:CD003408.

11. Yelderman M. Continuous measurement of cardiac output with the use of stochastic system identification techniques. J Clin Monit. 1990;6(4):322-32.

12. Liberati A, Altman DG, Tetzlaff J, Mulrow C, Gotzsche PC, loannidis JP, et al. The PRISMA statement for reporting systematic reviews and meta-analyses of studies that evaluate health care interventions: explanation and elaboration. Ann Intern Med. 2009;151(4):W65-94.

13. Critchley LA, Critchley JA. A meta-analysis of studies using bias and precision statistics to compare cardiac output measurement techniques. J Clin Monit Comput. 1999:15:85-91.

14. Whiting PF, Rutjes AW, Westwood ME, Mallett S, Deeks JJ, Reitsma JB, et al. QUADAS-2: a revised tool for the quality assessment of diagnostic accuracy studies. Ann Intern Med. 2011;155(8):529-36.

15. Joosten A, Desebbe O, Suehiro K, Murphy LS, Essiet M, Alexander B, et al. Accuracy and precision of non-invasive cardiac output monitoring devices in perioperative medicine: a systematic review and meta-analysis. Br J Anaesth. 2017;118(3):298-310

16. Saugel B, Hoppe P, Nicklas JY, Kouz K, Korner A, Hempel JC, et al. Continuous noninvasive pulse wave analysis using finger cuff technologies for arterial blood pressure and cardiac output monitoring in perioperative and intensive care medicine: a systematic review and meta-analysis. $\mathrm{Br} \mathrm{J}$ Anaesth. 2020;125(1):25-37.

17. DerSimonian R, Laird N. Meta-analysis in clinical trials. Control Clin Trials. 1986;7(3):177-88

18. Egger M, Davey Smith G, Schneider M, Minder C. Bias in meta-analysis detected by a simple, graphical test. BMJ. 1997;315(7109):629-34.

19. Viechtbauer W. Conducting meta-analyses in $\mathrm{R}$ with the metafor Package. J Stat Softw. 2010;36(3):48.

20. Akiyoshi K, Kandabashi T, Kaji J, Yamaura K, Yoshimura H, Irita K, et al. Accuracy of arterial pressure waveform analysis for cardiac output measurement in comparison with thermodilution methods in patients undergoing living donor liver transplantation. J Anesth. 2011;25(2):178-83.

21. Albert NM, Spear BT, Hammel J. Agreement and clinical utility of 2 techniques for measuring cardiac output in patients with low cardiac output. Am J Crit Care. 1999;8(1):464-74.

22. Bao FP, Wu J. Continuous versus bolus cardiac output monitoring during orthotopic liver transplantation. Hepatobiliary Pancreat Dis Int. 2008;7(2):138-44.

23. Bendjelid K, Schutz N, Suter PM, Romand JA. Continuous cardiac output monitoring after cardiopulmonary bypass: a comparison with bolus thermodilution measurement. Intensive Care Med. 2006;32(6):919-22.

24. Boldt J, Menges T, Wollbruck M, Hammermann H, Hempelmann G. Is continuous cardiac output measurement using thermodilution reliable in the critically ill patient? Crit Care Med. 1994;22(12):1913-8.

25. Bottiger BW, Rauch H, Bohrer H, Motsch J, Soder M, Fleischer F, et al. Continuous versus intermittent cardiac output measurement in cardiac surgical patients undergoing hypothermic cardiopulmonary bypass. J Cardiothorac Vasc Anesth. 1995;9(4):405-11.

26. Bottiger BW, Sinner B, Motsch J, Bach A, Bauer H, Martin E. Continuous versus intermittent thermodilution cardiac output measurement during orthotopic liver transplantation. Anaesthesia. 1997;52(3):207-14.

27. Bottiger BW, Soder M, Rauch H, Bohrer H, Motsch J, Bauer H, et al. Semicontinuous versus injectate cardiac output measurement in intensive care patients after cardiac surgery. Intensive Care Med. 1996;22(4):312-8.

28. Boyle M, Jacobs S, Torda TA, Shehabi Y. Assessment of the agreement between cardiac output measured by bolus thermodilution and continuous methods, with particular reference to the effect of heart rhythm. Aust Crit Care. 1997;10(1):5-8, 10-1.

29. Burchell SA, Yu M, Takiguchi SA, Ohta RM, Myers SA. Evaluation of a continuous cardiac output and mixed venous oxygen saturation catheter in critically ill surgical patients. Crit Care Med. 1997;25(3):388-91.

30. Button D, Weibel L, Reuthebuch O, Genoni M, Zollinger A, Hofer CK. Clinical evaluation of the FloTrac/Vigileo system and two established continuous cardiac output monitoring devices in patients undergoing cardiac surgery. Br J Anaesth. 2007;99(3):329-36.

31. Cathelyn J, Glenn LL. Effect of ambient temperature and cardiac stability on two methods of cardiac output measurement. J Cardiovasc Nurs. 1999;13(3):93-101.

32. Cecchini S, Schena E, Saccomandi P, Polisca F, Di Cecca I, Notaro M, et al. Cardiac output estimation in mechanically ventilated patients: a comparison between prolonged expiration method and thermodilution. Annu Int Conf IEEE Eng Med Biol Soc. 2012;2012:2708-11.

33. Cecconi M, Dawson D, Casaretti R, Grounds RM, Rhodes A. A prospective study of the accuracy and precision of continuous cardiac output monitoring devices as compared to intermittent thermodilution. Minerva Anestesiol. 2010;76(12):1010-7.

34. Cho YJ, Koo CH, Kim TK, Hong DM, Jeon Y. Comparison of cardiac output measures by transpulmonary thermodilution, pulse contour analysis, and pulmonary artery thermodilution during off-pump coronary artery bypass surgery: a subgroup analysis of the cardiovascular anaesthesia registry at a single tertiary centre. J Clin Monit Comput. 2016;30(6):771-82

35. Costa MG, Chiarandini P, Scudeller L, Vetrugno L, Pompei L, Serena G, et al. Uncalibrated continuous cardiac output measurement in liver transplant patients: LiDCOrapid system versus pulmonary artery catheter. J Cardiothorac Vasc Anesth. 2014;28(3):540-6.

36. Costa MG, Della Rocca G, Chiarandini P, Mattelig S, Pompei L, Barriga MS, et al. Continuous and intermittent cardiac output measurement in hyperdynamic conditions: pulmonary artery catheter vs lithium dilution technique. Intensive Care Med. 2008;34(2):257-63. 
37. Della Rocca G, Costa MG, Coccia C, Pompei L, Di Marco P, Vilardi V, et al. Cardiac output monitoring: aortic transpulmonary thermodilution and pulse contour analysis agree with standard thermodilution methods in patients undergoing lung transplantation. Can J Anaesth. 2003;50(7):707-11.

38. Della Rocca G, Costa MG, Pompei L, Coccia C, Pietropaoli P. Continuous and intermittent cardiac output measurement: pulmonary artery catheter versus aortic transpulmonary technique. $\mathrm{Br} J$ Anaesth. 2002:88(3):350-6.

39. Ditmyer CE, Shively M, Burns DB, Reichman RT. Comparison of continuous with intermittent bolus thermodilution cardiac output measurements. Am J Crit Care. 1995;4(6):460-5.

40. Ganter MT, Alhashemi JA, Al-Shabasy AM, Schmid UM, Schott P, Shalabi $\mathrm{SA}$, et al. Continuous cardiac output measurement by un-calibrated pulse wave analysis and pulmonary artery catheter in patients with septic shock. J Clin Monit Comput. 2016;30(1):13-22.

41. Greim CA, Roewer N, Thiel H, Laux G, SchulteamEsch J. Continuous cardiac output monitoring during adult liver transplantation: thermal filament technique versus bolus thermodilution. Anesth Analg. 1997:85(3):483-8.

42. Haller M, Zollner C, Briegel J, Forst H. Evaluation of a new continuous thermodilution cardiac output monitor in critically ill patients: a prospective criterion standard study. Crit Care Med. 1995;23(5):860-6.

43. Hamm JB, Nguyen BV, Kiss G, Wargnier JP, Jauffroy A, Helaine L, et al. Assessment of a cardiac output device using arterial pulse waveform analysis, Vigileo, in cardiac surgery compared to pulmonary arterial thermodilution. Anaesth Intensive Care. 2010;38(2):295-301.

44. Hogue CW Jr, Rosenbloom M, McCawley C, Lappas DG. Comparison of cardiac output measurement by continuous thermodilution with electromagnetometry in adult cardiac surgical patients. J Cardiothorac Vasc Anesth. 1994;8(6):631-5.

45. Ishihara H, Okawa H, Tanabe K, Tsubo T, Sugo Y, Akiyama T, et al. A new non-invasive continuous cardiac output trend solely utilizing routine cardiovascular monitors. J Clin Monit Comput. 2004;18(5-6):313-20.

46. Jacquet L, Hanique G, Glorieux D, Matte $\mathrm{P}$, Goenen M. Analysis of the accuracy of continuous thermodilution cardiac output measurement. Comparison with intermittent thermodilution and Fick cardiac output measurement. Intensive Care Med. 1996;22(10):1125-9.

47. Jakobsen CJ, Melsen NC, Andresen EB. Continuous cardiac output measurements in the perioperative period. Acta Anaesthesiol Scand. 1995;39(4):485-8.

48. Kotake $Y$, Moriyama K, Innami Y, Shimizu H, Ueda T, Morisaki H, et al. Performance of noninvasive partial $\mathrm{CO}_{2}$ rebreathing cardiac output and continuous thermodilution cardiac output in patients undergoing aortic reconstruction surgery. Anesthesiology. 2003;99(2):283-8.

49. Kotake $Y$, Yamada T, Nagata H, Suzuki T, Serita R, Katori N, et al. Improved accuracy of cardiac output estimation by the partial $\mathrm{CO}_{2}$ rebreathing method. J Clin Monit Comput. 2009;23(3):149-55.

50. Lazor MA, Pierce ET, Stanley GD, Cass JL, Halpern EF, Bode RH Jr. Evaluation of the accuracy and response time of STAT-mode continuous cardiac output. J Cardiothorac Vasc Anesth. 1997;1 1(4):432-6.

51. Le Tulzo Y, Belghith M, Seguin P, Dall'Ava J, Monchi M, Thomas R, et al. Reproducibility of thermodilution cardiac output determination in critically ill patients: comparison between bolus and continuous method. J Clin Monit. 1996;12(5):379-85.

52. Leather HA, Vuylsteke A, Bert C, M'Fam W, Segers P, Sergeant P, et al. Evaluation of a new continuous cardiac output monitor in off-pump coronary artery surgery. Anaesthesia. 2004;59(4):385-9.

53. Lefrant JY, Bruelle P, Ripart J, Ibanez F, Aya G, Peray P, et al. Cardiac output measurement in critically ill patients: comparison of continuous and conventional thermodilution techniques. Can J Anaesth. 1995:42(11):972-6.

54. Manecke GR Jr, Auger WR. Cardiac output determination from the arterial pressure wave: clinical testing of a novel algorithm that does not require calibration. J Cardiothorac Vasc Anesth. 2007;21(1):3-7.

55. McGee WT, Horswell JL, Calderon J, Janvier G, Van Severen T, Van den Berghe $G$, et al. Validation of a continuous, arterial pressure-based cardiac output measurement: a multicenter, prospective clinical trial. Crit Care. 2007;11(5):R105.

56. Mielck F, Buhre W, Hanekop G, Tirilomis T, Hilgers R, Sonntag H. Comparison of continuous cardiac output measurements in patients after cardiac surgery. J Cardiothorac Vasc Anesth. 2003;17(2):211-6.
57. Mihm FG, Gettinger A, Hanson CW 3rd, Gilbert HC, Stover EP, Vender $\mathrm{JS}$, et al. A multicenter evaluation of a new continuous cardiac output pulmonary artery catheter system. Crit Care Med. 1998;26(8):1346-50.

58. Monchi M, Thebert D, Cariou A, Bellenfant F, Joly LM, Brunet F, et al. Clinical evaluation of the Abbott Qvue-OptiQ continuous cardiac output system in critically ill medical patients. J Crit Care. 1998;13(2):91-5.

59. Nelson LD, Safcsak K, Cheatham ML, Block EF. Mathematical coupling does not explain the relationship between right ventricular end-diastolic volume and cardiac output. Crit Care Med. 2001;29(5):940-3.

60. Neto EP, Piriou V, Durand PG, Du Gres B, Lehot JJ. Comparison of two semicontinuous cardiac output pulmonary artery catheters after valvular surgery. Crit Care Med. 1999;27(12):2694-7.

61. Padua G, Canestrelli G, Pala G, Sechi D, Spanu MC. Original insight into continuous cardiac output monitoring: "TruCCOMS". Correlation with other methods. Miner Anestesiol. 2003;69(7-8):617-22, 22-4.

62. Peyton P. Hybrid measurement to achieve satisfactory precision in perioperative cardiac output monitoring. Anaesth Intensive Care. 2014:42(3):340-9.

63. Rauch H, Muller M, Fleischer F, Bauer H, Martin E, Bottiger BW. Pulse contour analysis versus thermodilution in cardiac surgery patients. Acta Anaesthesiol Scand. 2002;46(4):424-9.

64. Rodig G, Keyl C, Liebold A, Hobbhahn J. Intra-operative evaluation of a continuous versus intermittent bolus thermodilution technique of cardiac output measurement in cardiac surgical patients. Eur J Anaesthesiol. 1998;15(2):196-201.

65. Rodig G, Prasser C, Keyl C, Liebold A, Hobbhahn J. Continuous cardiac output measurement: pulse contour analysis vs thermodilution technique in cardiac surgical patients. Br J Anaesth. 1999;82(4):525-30.

66. Sakka SG, Reinhart K, Wegscheider K, Meier-Hellmann A. Is the placement of a pulmonary artery catheter still justified solely for the measurement of cardiac output? J Cardiothorac Vasc Anesth. 2000;14(2):119-24.

67. Schmid ER, Schmidlin D, Tornic M, Seifert B. Continuous thermodilution cardiac output: clinical validation against a reference technique of known accuracy. Intensive Care Med. 1999;25(2):166-72.

68. Seguin P, Colcanap O, Le Rouzo A, Tanguy M, Guillou YM, Malledant Y. Evaluation of a new semi-continuous cardiac output system in the intensive care unit. Can J Anaesth. 1998;45(6):578-83.

69. Singh A, Juneja R, Mehta Y, Trehan N. Comparison of continuous, stat, and intermittent cardiac output measurements in patients undergoing minimally invasive direct coronary artery bypass surgery. J Cardiothorac Vasc Anesth. 2002;16(2):186-90.

70. Thierry S, Thebert D, Brocas E, Razzaghi F, Van De Louw A, Loisance D, et al. Evaluation of a new invasive continuous cardiac output monitoring system: the truCCOMS system. Intensive Care Med. 2003;29(11):2096-9.

71. Yelderman ML, Ramsay MA, Quinn MD, Paulsen AW, McKown RC, Gillman $\mathrm{PH}$. Continuous thermodilution cardiac output measurement in intensive care unit patients. J Cardiothorac Vasc Anesth. 1992;6(3):270-4.

72. Zollner C, Goetz AE, Weis M, Morstedt K, Pichler B, Lamm P, et al. Continuous cardiac output measurements do not agree with conventional bolus thermodilution cardiac output determination. Can J Anaesth. 2001:48(11):1143-7.

73. Zollner C, Polasek J, Kilger E, Pichler B, Jaenicke U, Briegel J, et al. Evaluation of a new continuous thermodilution cardiac output monitor in cardiac surgical patients: a prospective criterion standard study. Crit Care Med. 1999;27(2):293-8.

74. Squara P, Scheeren TWL, Aya HD, Bakker J, Cecconi M, Einav S, et al. Metrology part 1: definition of quality criteria. J Clin Monit Comput. 2020;35(1):17-25.

75. Squara P, Scheeren TWL, Aya HD, Bakker J, Cecconi M, Einav S, et al. Metrology part 2: procedures for the validation of major measurement quality criteria and measuring instrument properties. J Clin Monit Comput. 2020;35(1):27-37.

76. Hapfelmeier A, Cecconi M, Saugel B. Cardiac output method comparison studies: the relation of the precision of agreement and the precision of method. J Clin Monit Comput. 2016;30(2):149-55.

77. Bland JM, Altman DG. Statistical methods for assessing agreement between two methods of clinical measurement. Lancet. 1986;1(8476):307-10.

78. Bland JM, Altman DG. Measuring agreement in method comparison studies. Stat Methods Med Res. 1999;8(2):135-60. 
79. Bland JM, Altman DG. Agreement between methods of measurement with multiple observations per individual. J Biopharm Stat. 2007;17(4):571-82.

80. Michard F. Thinking outside the (cardiac output) box. Crit Care Med. 2012;40(4):1361-2.

81. Medin DL, Brown DT, Wesley R, Cunnion RE, Ognibene FP. Validation of continuous thermodilution cardiac output in critically ill patients with analysis of systematic errors. J Crit Care. 1998;13(4):184-9.

82. Siegel LC, Hennessy MM, Pearl RG. Delayed time response of the continuous cardiac output pulmonary artery catheter. Anesth Analg. 1996;83(6):1173-7.

83. Aranda M, Mihm FG, Garrett S, Mihm MN, Pearl RG. Continuous cardiac output catheters: delay in in vitro response time after controlled flow changes. Anesthesiology. 1998;89(6):1592-5.

84. De Backer D, Vincent JL. The pulmonary artery catheter: is it still alive? Curr Opin Crit Care. 2018;24(3):204-8.

85. Vincent JL. The pulmonary artery catheter. J Clin Monit Comput. 2012;26(5):341-5.

86. De Backer D, Hajjar LA, Pinsky MR. Is there still a place for the SwanGanz catheter? We are not sure. Intensive Care Med. 2018:44(6):960-2.

87. Demiselle J, Mercat A, Asfar P. Is there still a place for the Swan-Ganz catheter? Yes. Intensive Care Med. 2018;44(6):954-6.

88. Teboul JL, Cecconi M, Scheeren TWL. Is there still a place for the SwanGanz catheter? No. Intensive Care Med. 2018;44(6):957-9.

89. Richard C, Warszawski J, Anguel N, Deye N, Combes A, Barnoud D, et al. Early use of the pulmonary artery catheter and outcomes in patients with shock and acute respiratory distress syndrome: a randomized controlled trial. JAMA. 2003;290(20):2713-20.

90. Harvey S, Harrison DA, Singer M, Ashcroft J, Jones CM, Elbourne D, et al. Assessment of the clinical effectiveness of pulmonary artery catheters in management of patients in intensive care (PAC-Man): a randomised controlled trial. Lancet. 2005;366(9484):472-7.

91. Chiang Y, Hosseinian L, Rhee A, Itagaki S, Cavallaro P, Chikwe J. Questionable benefit of the pulmonary artery catheter after cardiac surgery in high-risk patients. J Cardiothorac Vasc Anesth. 2015;29(1):76-81.

92. Seif A, Elliott RJ, Elsehety MA. Usage of Swan-Ganz catheterization during the past 2 decades in United States. J Crit Care. 2016;35:213-4.

93. Wiener RS, Welch HG. Trends in the use of the pulmonary artery catheter in the United States, 1993-2004. JAMA. 2007;298(4):423-9.

94. Peyton PJ, Chong SW. Minimally invasive measurement of cardiac output during surgery and critical care: a meta-analysis of accuracy and precision. Anesthesiology. 2010;113(5):1220-35.

95. Chong SW, Peyton PJ. A meta-analysis of the accuracy and precision of the ultrasonic cardiac output monitor (USCOM). Anaesthesia. 2012;67(11):1266-71.

\section{Publisher's Note}

Springer Nature remains neutral with regard to jurisdictional claims in published maps and institutional affiliations.
Ready to submit your research? Choose BMC and benefit from:

- fast, convenient online submission

- thorough peer review by experienced researchers in your field

- rapid publication on acceptance

- support for research data, including large and complex data types

- gold Open Access which fosters wider collaboration and increased citations

- maximum visibility for your research: over 100M website views per year

At BMC, research is always in progress.

Learn more biomedcentral.com/submissions 